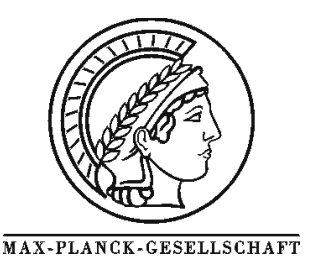

\title{
Reaction Pathways in $n$-Pentane Conversion Catalyzed by Tungstated Zirconia: Effects of Platinum in the Catalyst and Hydrogen in the Feed
}

\author{
S. Kuba, ${ }^{a, c}$ P. Lukinskas, ${ }^{a}$ R. Ahmad, ${ }^{b}$ F. C. Jentoft, ${ }^{b}$ R. K. Grasselli, ${ }^{a}$ B. C. Gates, ${ }^{a, c}$ and H. Knözinger ${ }^{a *}$ \\ ${ }^{a}$ Department Chemie, Physikalische Chemie, Ludwig-Maximilians-Universität München, Butenandtstr. 5-13, \\ Haus E, D-81377 München, Germany \\ ${ }^{\mathrm{b}}$ Department of Inorganic Chemistry, Fritz-Haber-Institute of the MPG, Faradayweg 4-6, 14195 Berlin, Germany \\ ${ }^{c}$ Department of Chemical Engineering and Materials Science, University of California, Davis, CA 95616, USA
}

* Corresponding author: e-mail helmut.knoezinger@cup.uni-muenchen.de, phone +49 89218077604,
fax +49 89218077605

Received 14 February 2003; accepted 15 May 2003

\begin{abstract}
The catalytic isomerization of $n$-pentane catalyzed by tungsted zirconia (WZ) was investigated to elucidate the effects of $\mathrm{H}_{2}$ in the feed and platinum in the catalyst. In the reaction catalyzed by WZ with or without platinum, when no $\mathrm{H}_{2}$ was present, a complex reaction network was observed, associated with organic deposits on the catalyst, giving mainly cracked products. The alkane is inferred to be activated in a redox step forming $\mathrm{W}^{5+}$ on the catalyst and unsaturated intermediates that react to form polyalkenylic surface species, which were detected by in-situ UVvisible spectroscopy. Promotion of WZ with platinum dramatically improved the catalytic activity and the isomerization selectivity in $n$-pentane conversion. The improvement was only marginal in the absence of $\mathrm{H}_{2}$, but it became substantial in the presence of $\mathrm{H}_{2}$, with the conversion increasing from 3 to $55 \%$ for the platinum-promoted catalyst, which underwent only little deactivation. The selectivity for isopentane was about $95 \%$ at $523 \mathrm{~K}$. The results indicate that the complex reaction network operative with the WZ catalyst is suppressed on the platinum-containing catalysts in the presence of $\mathrm{H}_{2}$. A fast and selective monomolecular isomerization reaction takes over in this case. The adsorbed unsaturated $\mathrm{C}_{5}$ intermediates are rapidly desorbed via hydrogenation on the reduced tungstate surface. This rapid desorption minimizes the formation of highermolecular-weight organic species such as polyalkenyls that are necessary for the complex reaction path observed with the unpromoted catalyst. The observed side products are interpreted not as cracking products accompanying the acid-catalyzed isomerization reaction but instead as hydrogenolysis products formed directly on the platinum particles.
\end{abstract}

Keywords: Tungstated zirconia; $n$-Pentane conversion; Platinum—effect of; H2—effect of

\section{Introduction}

Sulfated Zirconia (SZ) and tungstated zirconia (WZ) have drawn wide interest as candidate catalysts to replace those applied for skeletal isomerization of alkanes (1-10). SZ (1-5) has the advantage of being highly active and capable of catalyzing the isomerization reactions at low temperatures that favor thermodynamically the formation of branched alkanes $(2,4)$, but this catalyst undergoes rapid and irreversible deactivation (11-13). Although WZ is less active than SZ (requiring temperatures greater than about $500 \mathrm{~K}$ ), when it is promoted by a noble metal and a transition metal oxide it is almost $100 \%$ selective for branched alkanes (14) and undergoes only slow deactivation (14), which is not irreversible when the catalyst is properly prepared (15).

Extensive work has been devoted to the preparation and structural characterization of WZ catalysts (7-10,16-18). Active samples are typically prepared by impregnation of amorphous zirconium hydroxide with aqueous solutions 
containing the tungstate precursor (6-9) or by coprecipitation from aqueous solutions containing $\mathrm{ZrOCl}_{2}$ and the tungstate precursor (18). These steps are followed by drying and calcination at temperatures between 873 and $1073 \mathrm{~K}$, leading to crystallization of the zirconia support. The tungsten typically stabilizes the high-temperature tetragonal modification of zirconia (7-9,16-18). The tungsten species are present as three-dimensional surface tungstates after calcination, provided that the tungsten content remains below the theoretical monolayer capacity (9). The tungsten atoms in the surface tungstates are octahedrally coordinated (9), interconnected via $\mathrm{W}-\mathrm{O}-\mathrm{W}$ bridges $(9,16)$, and anchored to the support by W-O-Zr bonds (9).

To achieve high activities and selectivities of WZ, promotion with a noble metal (Pt or Pd) is essential. The preparation of the unpromoted $\mathrm{WZ}$ is therefore typically followed by impregnation with a platinum-containing component. The promoted catalysts exhibit high activities and selectivities for the isomerization of light alkanes only when $\mathrm{H}_{2}$ is present in the reaction mixture $(7,8,14)$. Consequently, most literature reports of platinum-promoted $\mathrm{WZ}$ present data for the catalyst operating in the presence of $\mathrm{H}_{2}(7,8,20$ 26 ), and there is little literature of the unpromoted catalysts, although they are active for the isomerization reaction $(9,19)$. Even for the platinum-promoted catalyst, full analyses of the reaction products are usually lacking, and the role of $\mathrm{H}_{2}$ in the reaction is not well known, although some investigations have reported its positive effects $(7,8,20-26)$.

To fill the gaps in the reported work and provide a better basis for inferring the reaction networks and mechanisms and ultimately guiding the development of improved catalysts, we investigated the catalytic performance of both unpromoted and platinum-promoted $\mathrm{WZ}$ for isomerization of $n$-pentane in the presence and in the absence of $\mathrm{H}_{2}$. The experiments were carried out under a single set of conditions to facilitate elucidation of the effects of the platinum and $\mathrm{H}_{2}$, and all the detectable catalytic reaction products were identified.

\section{Experimental}

\section{Catalyst preparation}

WZ samples were prepared by impregnation of amorphous $\mathrm{Zr}(\mathrm{OH})_{4}$ (MEL Chemicals, XZO880/01) with an aqueous solution of ammonium metatungstate $\left(\left(\mathrm{NH}_{4}\right)_{6} \mathrm{H}_{2} \mathrm{~W}_{12} \mathrm{O}_{40} \cdot \mathrm{nH}_{2} \mathrm{O}\right)$ (Aldrich)), as before (9). The resulting suspension was refluxed overnight at $393 \mathrm{~K}$ and dried in an oven at $353 \mathrm{~K}$ prior to calcination. The samples were then calcined at $923 \mathrm{~K}$ in static air for $3 \mathrm{~h}$. The surface area of this material was $132 \mathrm{~m}^{2} / \mathrm{g}$.

The concentration of tungsten in the preparation solution was chosen to give a nominal tungsten loading of $17.7 \mathrm{wt} \% \mathrm{WO}_{3}$ in the catalyst, which compares with the estimated theoretical monolayer capacity of $19 \mathrm{wt} \% \mathrm{WO}_{3}$ based on the area of a $\mathrm{WO}_{3}$ unit (9). To incorporate platinum, the WZ sample was impregnated in a second step with a 0.6- $M$ aqueous solution of $\operatorname{Pt}\left(\mathrm{NH}_{3}\right)_{4}\left(\mathrm{NO}_{3}\right)_{2}$ by the incipient wetness technique. The concentration and amount of the solution were chosen to give a nominal platinum catalyst loading of $1 \mathrm{wt} \%$. The freshly impregnated catalyst, denoted
PtWZ, was dried at $383 \mathrm{~K}$ for $12 \mathrm{~h}$ and calcined for $3 \mathrm{~h}$ at $873 \mathrm{~K}$ in air. This material had a surface area of $126 \mathrm{~m}^{2} / \mathrm{g}$ which is essentially identical to that of platinum-free WZ.

\section{Catalytic testing}

The catalytic conversion of $n$-pentane was carried out in a tubular once-through packed-bed flow reactor at $523 \mathrm{~K}$ and atmospheric pressure; $200 \mathrm{mg}$ of catalyst powder was mixed with $1 \mathrm{~g}$ of inert, nonporous $\alpha-\mathrm{Al}_{2} \mathrm{O}_{3}$ for each experiment. The reactant stream consisted of $1 \mathrm{vol} \% n$-pentane in $\mathrm{N}_{2}$ at a flow rate of $10.0 \mathrm{ml} \mathrm{min}^{-1}$ (all gas flow rates are given at approximately NTP). $\mathrm{H}_{2}$ was sometimes added by mixing a flow of $\mathrm{H}_{2}$ of $2.0 \mathrm{ml} \mathrm{min}^{-1}$ into the reactant feed, giving a total flow rate of $12.0 \mathrm{ml} \mathrm{min}$. The product was analyzed with an on-line gas chromatograph equipped with a 30-m alumina PLOT capillary column (inner diameter, $0.53 \mathrm{~mm}$ ) and a flame ionization detector. The first injection was done after $7 \mathrm{~min}$ time-on-stream (TOS) followed by subsequent injections every $11.5 \mathrm{~min}$ for $2.5 \mathrm{~h}$.

Prior to each reaction experiment, the catalyst was pretreated in dry $\mathrm{O}_{2}\left(10.0 \mathrm{ml} \mathrm{min}^{-1}\right)$ at $673 \mathrm{~K}$ for $1 \mathrm{~h}$. The catalyst was then cooled to the reaction temperature of $523 \mathrm{~K}$ and purged with $\mathrm{He}\left(30.0 \mathrm{ml} \mathrm{min}^{-1}\right)$ for $30 \mathrm{~min}$ to remove all the $\mathrm{O}_{2}$. When the catalyst was prereduced in $\mathrm{H}_{2}$, the sample was first treated in $\mathrm{O}_{2}$ as described above, purged with $\mathrm{He}$ at $673 \mathrm{~K}$, and then reduced at $673 \mathrm{~K}$ in flowing $\mathrm{H}_{2}$ $\left(10.0 \mathrm{ml} \mathrm{min}^{-1}\right)$ and cooled to the reaction temperature in flowing $\mathrm{H}_{2}$.

In some experiments, the catalytic hydrogenation of propene was investigated; $200 \mathrm{mg}$ of catalyst was pretreated for $1 \mathrm{~h}$ at $723 \mathrm{~K}$ in flowing $\mathrm{O}_{2}\left(20.0 \mathrm{ml} \mathrm{min}{ }^{-1}\right)$. The catalyst was then cooled in flowing $\mathrm{He}\left(20.0 \mathrm{ml} \mathrm{min}^{-1}\right)$ to the reaction temperature of $523 \mathrm{~K}$ and kept under these conditions for $30 \mathrm{~min}$. The reaction was carried out with the following flow rates $\left(\mathrm{ml} \mathrm{min}^{-1}\right)$ : $\mathrm{He}, 15.0$; propene, 1.5 ; and $\mathrm{H}_{2}, 4.0$.

\section{In-situ UV-visible spectroscopy}

A Perkin-Elmer Lamda 9 UV-visible spectrometer was equipped with a home-made UV-visible quartz cell that served as a reactor allowing high catalyst temperatures and flow of reactant gases (27). The scan speed was $240 \mathrm{~nm} \mathrm{~min}^{-}$ ${ }^{1}$, and the spectral resolution was $5 \mathrm{~nm}$. A commercial Spectralon sample was used as a white standard. The WZ catalyst (900 mg) was pretreated in flowing $\mathrm{O}_{2}\left(30.0 \mathrm{ml} \mathrm{min}^{-1}\right)$ for $1 \mathrm{~h}$ and then cooled to the reaction temperature of $523 \mathrm{~K}$. The cell was then purged with $\mathrm{He}\left(30.0 \mathrm{ml} \mathrm{min}^{-1}\right)$ for $30 \mathrm{~min}$, and the reaction was started by flowing a mixture of 1 vol\% $n$-pentane in He through the catalyst bed. For a period of $3.5 \mathrm{~h}$, a UV-visible spectrum was recorded every 3 min while the catalytic conversions and selectivities were measured simultaneously by on-line gas chromatography to test the comparability of the catalyst performance data with those obtained in the standard tubular flow reactor.

\section{Data Analysis}

The mole fraction (partial pressure) ${ }^{\mathrm{i}} P_{n}$ of each product component $n$ containing $i$ carbon atoms was determined 
from the GC analyses and used to calculate the normalized conversion ${ }^{i} X_{n}$ :

$$
{ }^{\mathrm{i}} \mathrm{X}_{\mathrm{n}}=\frac{\left(\frac{\mathrm{i}}{5}\right) \cdot{ }^{\mathrm{i}} \mathrm{P}_{\mathrm{n}}}{\sum_{\mathrm{n}}\left(\frac{\mathrm{i}}{5}\right) \cdot{ }^{\mathrm{i}} \mathrm{P}_{\mathrm{n}}}
$$

The normalized total $n$-pentane conversion (a measure of the catalytic activity) is the sum of the normalized conversions to the various products:

$$
X_{n \text {-pentane }}=\sum_{n}{ }^{i} X_{n}
$$

To determine the specific rates of the $n$-pentane conversion from differential conversion data, $r_{n \text {-pentane, }} X_{n \text {-pentane }}$ was multiplied by the number of moles of $n$-pentane $n_{n \text {-pentane }}$ passing through the reactor per unit time and divided by the BET surface area $\left(A_{\mathrm{BET}}\right)$ of the catalyst, the units of the rate thus being $\mathrm{mol} \cdot \mathrm{m}^{-2} \cdot \mathrm{s}^{-1}$ :

$$
r_{n-\text { pentane }}=\frac{X_{n-\text { pentane }} \cdot n_{n-\text { pentane }}}{A_{B E T}}
$$

The selectivity for isopentane is then given as

$$
S=\frac{X_{\text {isopentane }}}{X_{n \text {-pentane }}} \cdot 100
$$

The rate of the formation of each side product $r_{n}$ is calculated analogously:

$r_{n}=\left(\frac{5}{i}\right) \frac{X_{n} \cdot n_{n-\text { pentane }}}{A_{B E T}}$

In the analysis of the UV-visible spectra, the KubelkaMunk function $\left(\mathrm{F}\left(\mathrm{R}_{\infty}\right)\right)$ was used to convert the reflectance measurements $\left(\mathrm{R}_{\infty}\right)$ into equivalent absorption spectra:

$$
F\left(R_{\infty}\right)=\frac{\left(1-R_{\infty}\right)^{2}}{2 R_{\infty}}
$$

A spectrum taken at $523 \mathrm{~K}$ with the sample in $\mathrm{He}$ was used as a reference for the determination of difference spectra.

\section{Results}

The conversions of $n$-pentane were less then $5 \%$ (and assumed to be differential), except when the catalyst was PTWZ in the presence of $\mathrm{H}_{2}$. When the conversions were lowest $(\approx 1 \%)$, the values of the normalized total conversion and selectivity for isopentane were reproduced within $10 \%$.

\section{Catalysis by unpromoted WZ}

The rate of the reaction catalyzed by $\mathrm{WZ}$ without platinum at $523 \mathrm{~K}$ (calculated from the differential conversion data) and the selectivity changed with time on stream (TOS), as shown in Fig. 1 for reaction in the absence of feed $\mathrm{H}_{2}$. The trends match those reported (10). After an induction period of approximately $20 \mathrm{~min}$, a maximum conversion of $0.87 \%$ (corresponding to a rate of $2.4 \cdot 10^{-11} \mathrm{~mol} \cdot \mathrm{m}^{-2} \cdot \mathrm{s}^{-1}$ ) was reached. Subsequently, fast deactivation and stabilization at a lower conversion of about $0.20 \%$ (corresponding to a rate of $\left.6.0 \cdot 10^{-12} \mathrm{~mol} \cdot \mathrm{m}^{-2} \cdot \mathrm{s}^{-1}\right)$ was observed within ca. $90 \mathrm{~min}$.

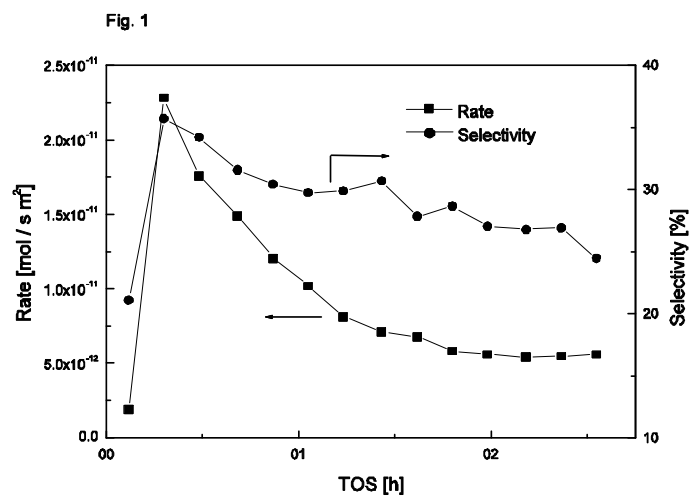

Fig. 1. Rate of $n$-pentane conversion and selectivity for isopentane formation in catalysis by $\mathrm{WZ}$ in the absence of $\mathrm{H}_{2}$ in the feed.

After approximately $2 \mathrm{~h}$ TOS, the isopentane selectivity was stabilized at approximately $27 \%$. Side products formed in the absence of $\mathrm{H}_{2}$ in the feed were mainly saturated cracked products, namely, propane, isobutane, and $n$-butane. Small amounts of unsaturated cracked products and of pentenes were also formed. Methane, ethane, and neopentane were not detected. The dependence of the rates of formation of isopentane and saturated cracked products on TOS is shown in Fig. 2. The rate of formation of the alkane side products follows a trend paralleling that of isopentane formation. The ratios of the rates of formation of propane, isobutane, $n$-butane, and isopentane remained essentially constant and independent of the conversion at values of 0.6:0.9:0.2:1.0, respectively. The selectivities for formation of these products were essentially independent of TOS.

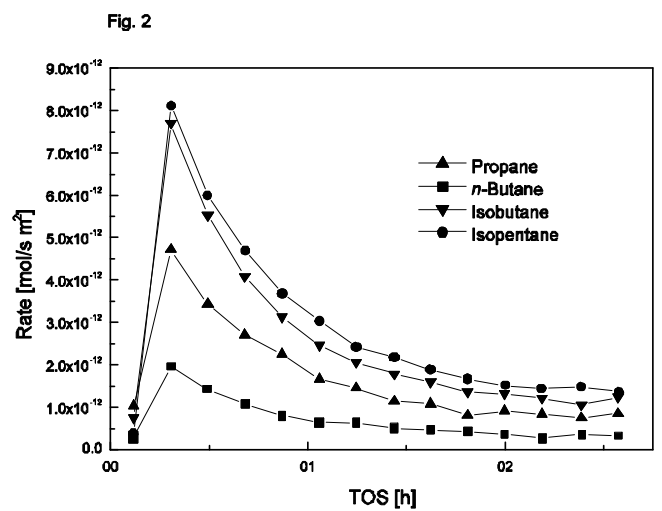

Fig. 2. Rates of formation of the various alkane products in the reaction of n-pentane on the $\mathrm{WZ}$ catalyst in the absence of $\mathrm{H} 2$ in the feed.

To investigate the influence of $\mathrm{H}_{2}$ on the $n$-pentane conversion, experiments were carried out (a) by mixing $\mathrm{H}_{2}$ into the reactant feed stream and (b) using prereduced catalysts. In the presence of $\mathrm{H}_{2}$ the observed maximum conversion of $0.34 \%$ (corresponding to a rate of $9.0 \cdot 10^{-12} \mathrm{~mol} \cdot \mathrm{m}^{-2} \cdot \mathrm{s}$ ${ }^{1}$ ), was reached after $30 \mathrm{~min}$ TOS (the induction period); the rate is lower than that in the absence of $\mathrm{H}_{2}\left(2.4 \cdot 10^{-11} \mathrm{~mol} \cdot \mathrm{m}^{-}\right.$ ${ }^{2} \cdot \mathrm{s}^{-1}$ ) (Fig. 3). Stable activity corresponding to a rate of 


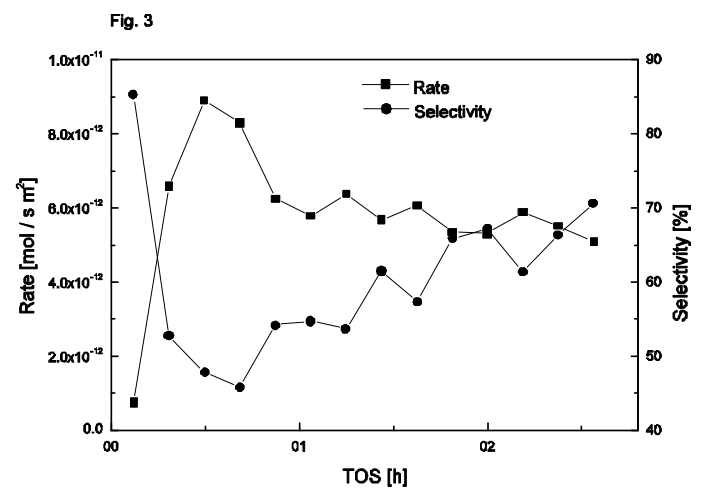

Fig. 3. Rate of n-pentane conversion and selectivity for isopentane in catalysis by $\mathrm{WZ}$ in the presence of $\mathrm{H} 2$ in the feed.

$6.0 \cdot 10^{-12} \mathrm{~mol} \mathrm{~m}^{-2} \mathrm{~s}^{-1}$ was attained after ca. $1 \mathrm{~h}$. The isopentane selectivity dropped steeply in the first $30 \mathrm{~min}$, passed through a minimum of ca. $40-45 \%$ at a TOS corresponding to the maximum total rate of conversion, and then slowly increased to $60 \%$ after $2.5 \mathrm{~h}$ (Fig. 3). As shown in Fig. 4, the dependence of the rates of formation of the side products on TOS closely resembles that observed for the reaction in the absence of $\mathrm{H}_{2}$, with isobutane being the main side product and propane and $n$-butane being the next most important ones. Unsaturated products were barely observed, and methane, ethane, and neopentane were not observed.

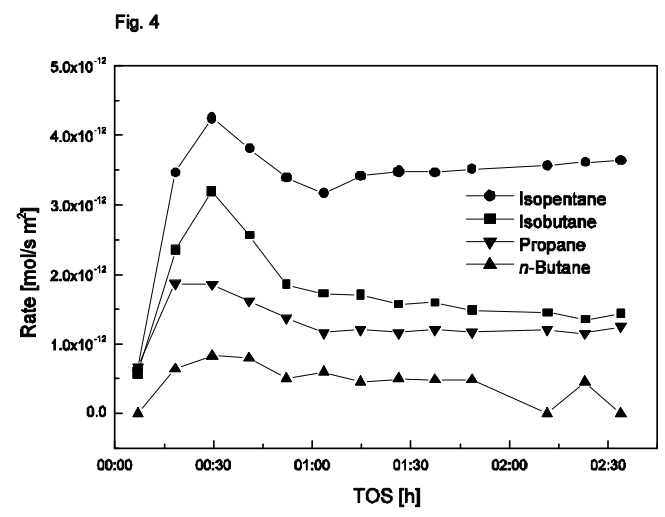

Fig. 4. Rates of formation of alkanes in the reaction of n-pentane on the WZ catalyst in the presence of $\mathrm{H} 2$ in the feed.

However, in contrast to these similarities between the reactions in the absence and presence of $\mathrm{H}_{2}$, the ratio of the rate of formation of isopentane to those of the side products did not remain constant with TOS. The rates of formation of the side products decreased after the maximum in rate of $n$ pentane conversion had been attained, but the rate of isopentane formation increased slightly with increasing TOS (preceded by an initial decrease after the rate maximum), thus leading to the observed increase in selectivity shown in Fig. 3.

When the WZ catalyst was prereduced in $\mathrm{H}_{2}$, no induction period was observed. The maximum rate of $1.5 \cdot 10^{-11} \mathrm{~mol} \cdot \mathrm{m}^{-2} \cdot \mathrm{s}^{-1}$ was observed at the lowest measurable
TOS. After ca. $30 \mathrm{~min}$, the rate started to decrease with TOS (Fig. 5). The selectivity for isopentane remained approximately constant between 50 and $60 \%$ over the course of an experiment.

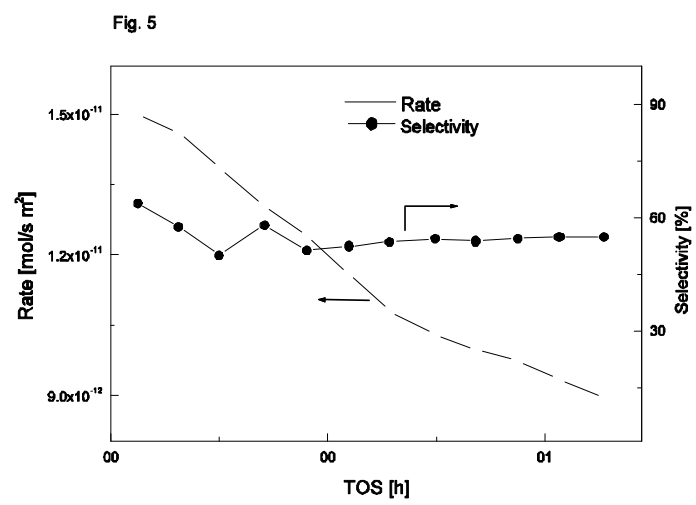

Fig. 5. Rates of n-pentane conversion and selectivity for isopentane in catalysis by prereduced $\mathrm{WZ}$ in the absence of $\mathrm{H} 2$ in the feed.

The dependence of the rates of formation of the side products on TOS is shown in Fig. 6. The major product, isopentane, was formed at a maximum conversion at the beginning of the experiment $(0.37 \%)$. After ca. $2.0 \mathrm{~h}$, the conversion to isopentane stabilized at a value of about $0.20 \%$ (with a rate of $5.0 \cdot 10^{-12} \mathrm{~mol} \cdot \mathrm{m}^{-2} \cdot \mathrm{s}^{-1}$ ). The major side products (in decreasing order of rate of formation) were isobutane $>$ propane $>n$-butane; traces of butenes and pentenes were also observed. The rates of formation of these products decreased slightly with increasing TOS until stable rates were attained. The near steady-state conversions of formation were $0.07 \%$ (with a rate of $2.0 \cdot 10^{-12} \mathrm{~mol} \cdot \mathrm{m}^{-2} \cdot \mathrm{s}^{-1}$ ) for isobutane and $0.03 \%$ (with a rate of $0.7 \cdot 10^{-12} \mathrm{~mol} \cdot \mathrm{m}^{-2} \cdot \mathrm{s}^{-1}$ ) for $n$-butane. Pentenes were formed at a nearly constant conversion of $0.01 \%$ (with a rate of $0.2 \cdot 10^{-12} \mathrm{~mol} \cdot \mathrm{m}^{-2} \cdot \mathrm{s}^{-1}$ ). Butenes, propene, and ethene were not detected in the products.

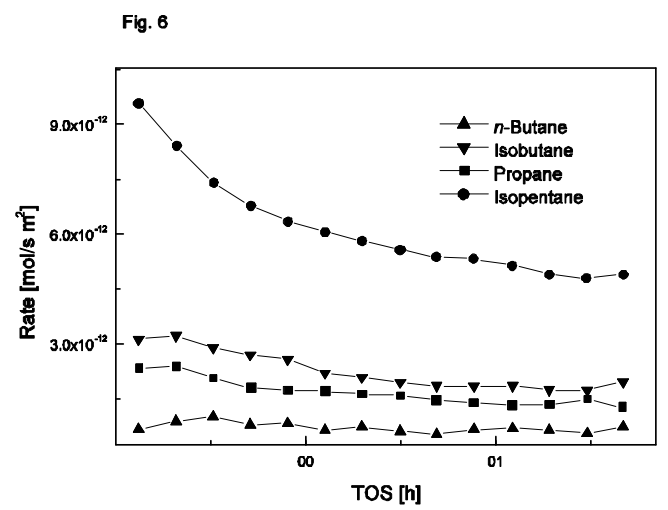

Fig. 6. Rates of formation of the various alkane products in the reaction of n-pentane on the H2-prereduced WZ catalyst in the absence of $\mathrm{H} 2$ in the feed.

To provide a basis for determining whether the unpromoted WZ had dehydrogenation activity, experiments were done to investigate, the hydrogenation of propene. 
Propane was formed at $523 \mathrm{~K}$ from a mixture of propene and $\mathrm{H}_{2}$; products with carbon numbers greater than three, mainly isobutane, were also formed. The time dependence of the rate of isobutane formation is different from that observed for the rate of propane formation. At low TOS the ratio of the rate of formation of propane to that of isobutane was $<1$, and it became $>1$ at longer TOS. When the propene hydrogenation was carried out with a prereduced WZ catalyst, closely similar behavior was observed, except that the activity was higher.

\section{Catalysis by platinum-promoted WZ}

When the $n$-pentane conversion was catalyzed by PtWZ in the absence of $\mathrm{H}_{2}$, the maximum total conversion at $523 \mathrm{~K}$ was $2.5 \%$ (with a rate of $7.0 \cdot 10^{-11} \mathrm{~mol} \cdot \mathrm{m}^{-2} \cdot \mathrm{s}^{-1}$ ) (Fig. 7 ), which is three times that of the conversion catalyzed by platinum-free WZ. The maximum conversion in the pres-

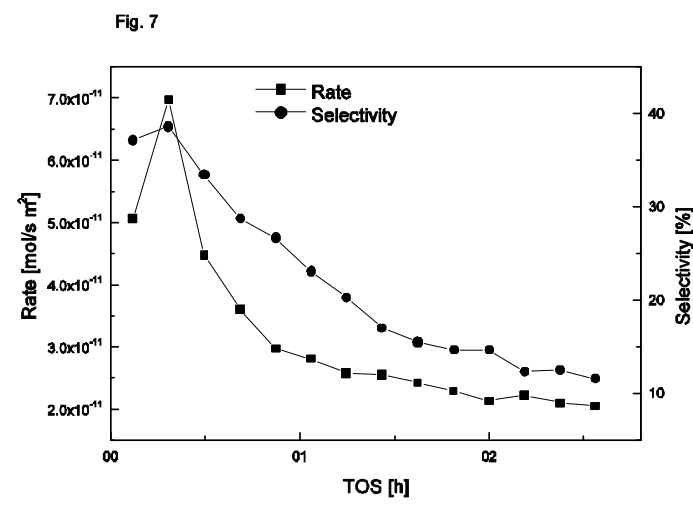

Fig. 7. Rate of the total n-pentane conversion and selectivity for isopentane in catalysis by PtWZ in the absence of $\mathrm{H} 2$ in the feed.

ence of the promoted catalyst was attained after an induction period of ca. $20 \mathrm{~min}$, followed by deactivation for about $2 \mathrm{~h}$, after which the steady-state rate of $2.2 \cdot 10^{-11} \mathrm{~mol} \cdot \mathrm{m}^{-2} \cdot \mathrm{s}^{-1}$ was observed. The higher activity is associated with the formation of more significant amounts of unsaturated products (mainly pentenes) than were observed with the unpromoted catalyst. The saturated products (Fig. 8) nearly match those observed with the unpromoted catalyst, but propene, butenes, and pentenes were formed in addition with the promoted catalyst. The time dependence of the rate of formation of the saturated products resembles that observed with the unpromoted catalyst. The selectivity to isopentane observed with PtWZ decreased from about 35 to $15 \%$ with increasing TOS (Fig. 7). The lower isopentane selectivity resulting from the addition of promoter to the catalyst is associated with the formation of large amounts of unsaturated products.

When $\mathrm{H}_{2}$ was added to the feed containing $n$-pentane in the conversion catalyzed by PtWZ, marked increases in activity and selectivity were observed. As shown in Fig. 9, the $n$-pentane conversion reached a stable value of $53 \%$ after ca. $30 \mathrm{~min}$ TOS, and this rate is 60 times higher than that observed with the Pt-free WZ catalyst. However, the total conversion was now close to the equilibrium value $(70 \%)$, so that a direct comparison of rates is no longer meaningful. More important, a significant increase in the selectivity for formation of isopentane was observed, with values being about $95 \%$.

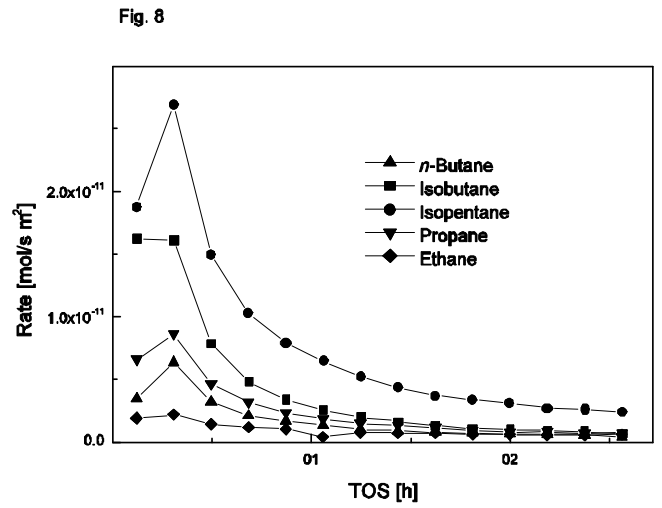

Fig. 8. Rates of formation of the various alkane products in the reaction of n-pentane on the PtWZ catalyst in the absence of $\mathrm{H} 2$ in the feed.

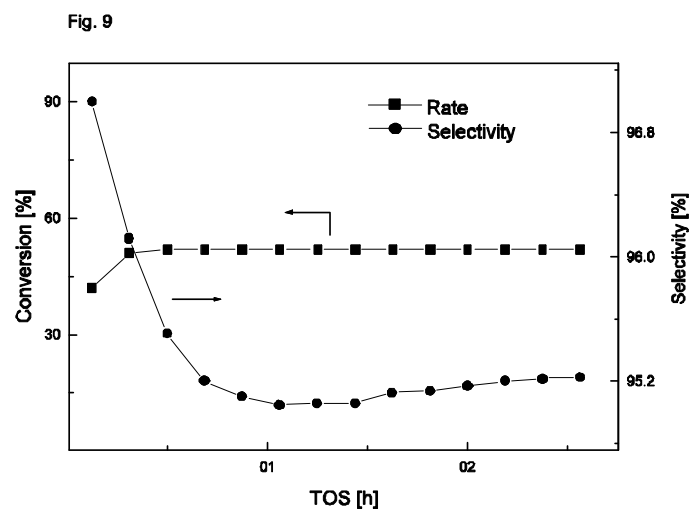

Fig. 9. Rate of n-pentane conversion and selectivity for isopentane in catalysis by PtWZ in the presence of $\mathrm{H} 2$ in the feed.

A summary comparison of the catalytic performance of WZ with that of PtWZ in the presence and absence of $\mathrm{H}_{2}$ is given in Table 1. The distribution of side products observed for reaction catalyzed by PtWZ in the presence of $\mathrm{H}_{2}$ (Fig. 10) is different from that observed with the unpromoted catalyst or the promoted catalyst in the absence of $\mathrm{H}_{2}$. In the latter two cases, isobutane was the most abundant side product, followed by propane and $n$-butane. In the reaction catalyzed by PtWZ, propane and ethane were the main side products, followed by methane and $n$-butane, with only smaller conversions to isobutane. Ethane and propane were formed in equimolar amounts. The methane formation in this experiment could not be quantified (and data are not shown), but the results of separate experiments show that methane was formed in equimolar ratios with butanes. 
Table 1: Summary of the catalytic performance of the WZ and PtWZ catalyst for $n$-pentane conversion in the presence and absence of $\mathrm{H}_{2}$ in the feed.

\begin{tabular}{|c|c|c|c|c|}
\hline Catalyst & $\mathrm{H}_{2}$ in feed? & $\begin{array}{c}\text { Conversion of } \\
\text { n-pentane }\end{array}$ & $\begin{array}{l}\text { max. rate } \\
{\left[\mathrm{mol} / \mathrm{s} \cdot \mathrm{m}^{2}\right]}\end{array}$ & $\begin{array}{c}\text { Selectivity } \\
\text { Isopentane } \\
{[\%]}\end{array}$ \\
\hline \multirow[t]{2}{*}{$W Z$} & No & $0.87 \%$ & $2.4 \cdot 10^{-11}$ & $\sim 30$ \\
\hline & Yes & $0.37 \%$ & $9.0 \cdot 10^{-11}$ & $40-60$ \\
\hline \multirow[t]{2}{*}{ PtWZ } & No & $2.5 \%$ & $7.0 \cdot 10^{-11}$ & $15-35$ \\
\hline & Yes & $55 \%$ & $\geq 1.4 \cdot 10^{-9} \mathrm{a}$ & 95 \\
\hline
\end{tabular}

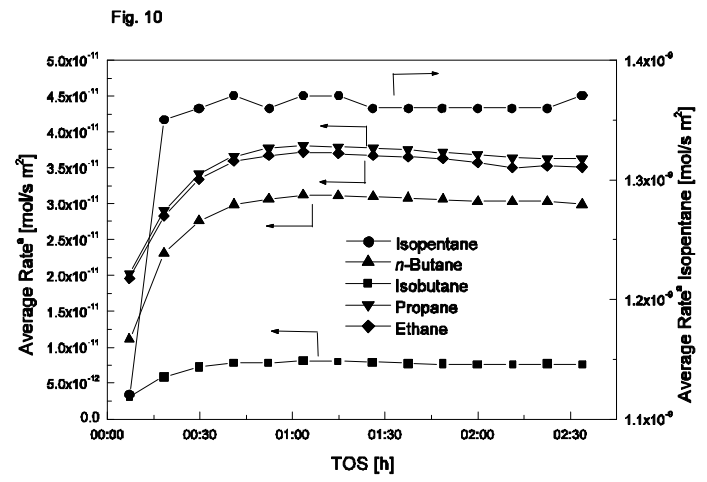

Fig. 10. Average rates of formation of the various alkane products in the reaction of $n$-pentane on the PtWZ catalyst in the presence of $\mathrm{H} 2$ in the feed. a The conversions in the experiment represented here were greater than differential, and so true rates could not be determined

The TOS dependence of the rates of formation of the various products on the prereduced PtWZ catalyst is complex. As shown in Fig. 11, there was no induction period,

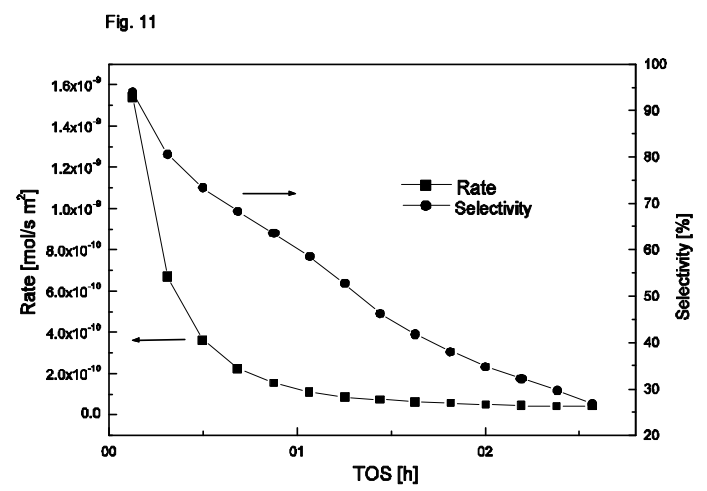

Fig. 11. Rate of n-pentane conversion and selectivity for isopentane in catalysis on prereduced PtWZ in the absence of $\mathrm{H} 2$ in the feed. and the initial conversion of $94 \%$ decreased monotonically with increasing TOS. The isopentane selectivity, however, decreased almost linearly with TOS from an initial value of ca. $90 \%$ to $25 \%$ after $2.5 \mathrm{~h}$. The side products were mainly butenes and pentenes, and alkanes were formed at low conversions, not exceeding 1\%. As shown in Fig. 12, the rate of isopentane formation decreased steeply within the first ca. $40 \mathrm{~min}$. In contrast, the other products were formed with nearly constant and nearly identical rates. The conversion to the pentenes attained a maximum after ca. 20 min and then stabilized after $1 \mathrm{~h}$ at $0.8 \%$. The rates of formation of the other unsaturated products increased with TOS, but conversions to these products never exceeded a value of $0.02 \%$.

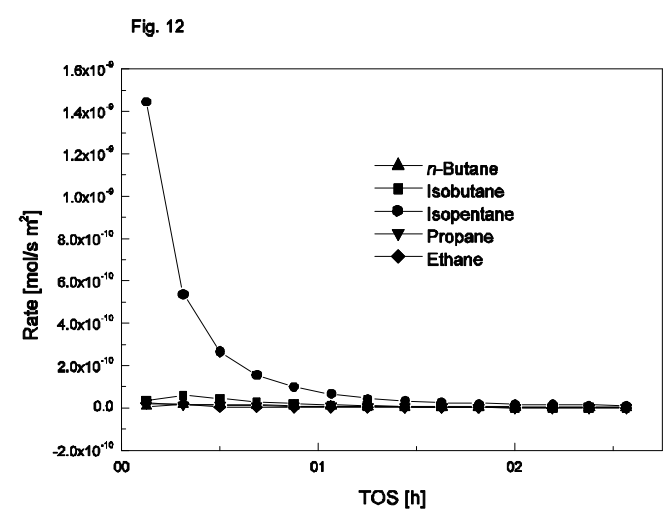

Fig. 12. Rates of formation of the various alkane products in the reaction of $n$-pentane catalyzed by $\mathrm{H}_{2}$-prereduced PtWZ in the absence of $\mathrm{H}_{2}$ in the feed.

\section{In-situ UV-visible spectroscopy of surface species}

The $n$-pentane isomerization was carried out in the presence of each of the catalysts, WZ and PtWZ, in a hightemperature UV-visible spectroscopy cell in the absence and 
in the presence of $\mathrm{H}_{2}$. The results represent the UV-visible difference spectra in the range beyond $355 \mathrm{~nm}$ recorded during the $n$-pentane reaction on $\mathrm{WZ}$ in the absence (Fig.13) and in the presence (Fig.14) of $\mathrm{H}_{2}$. The in-situ spectra of the two catalysts are similar to each other.

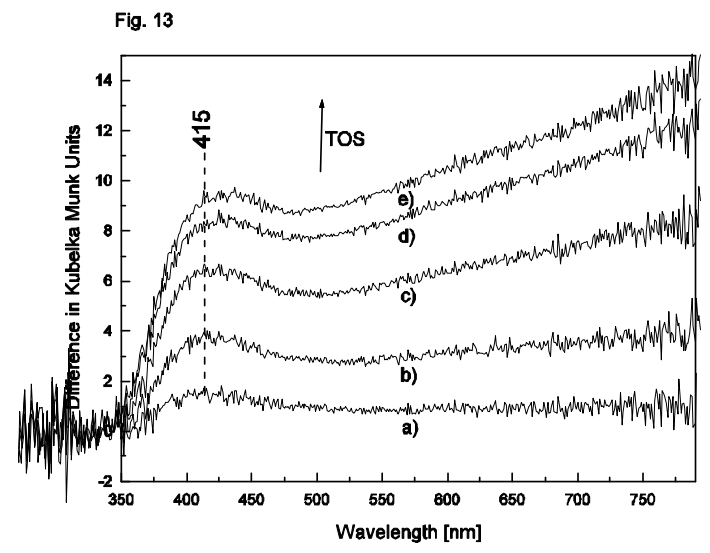

Fig. 13. UV-visible difference spectra obtained for the working $\mathrm{WZ}$ catalyst for $\mathrm{n}$-pentane isomerization on $\mathrm{WZ}$ in absence of H2: a, TOS = 15 min; b, 30 min; c, 1 h; d, 2 h; e, $3 \mathrm{~h}$.

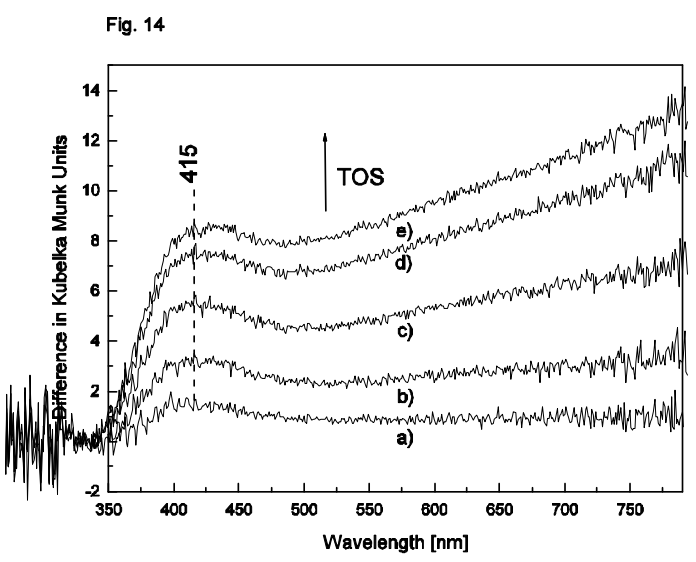

Fig. 14. UV-visible difference spectra obtained for the working $\mathrm{WZ}$ catalyst for n-pentane isomerization on $\mathrm{WZ}$ in the presence of $\mathrm{H} 2$ in the feed: $\mathrm{a}, \mathrm{TOS}=15 \mathrm{~min}$; b, $30 \mathrm{~min}$; c, $1 \mathrm{~h} ; \mathrm{d}, 2 \mathrm{~h}$; e, $3 \mathrm{~h}$.

The absorption in the entire observed wavelength range increased with TOS. A band at $415 \mathrm{~nm}$ developed during the few first minutes on stream. At TOS values exceeding $30 \mathrm{~min}$, this band shifted to higher wavelengths and reached a value of $440 \mathrm{~nm}$ after several hours.

The absorption of the PtWZ catalyst in the range beyond the bandgap $(\sim 350 \mathrm{~nm})$ indicates only a low reflectance of about $20-30 \%$, even prior to reaction. Consequently, the signal-to-noise ratio of the in-situ spectra was low. After the reaction had started in the absence of $\mathrm{H}_{2}$, the absorption in the entire spectral range beyond $350 \mathrm{~nm}$ increased, and the band at $415 \mathrm{~nm}$ (present in the spectrum of WZ) grew in (data not shown), and a red shift of this band was observed. However, the spectra during the reaction on the PtWZ sample in the presence of $\mathrm{H}_{2}$ remained unchanged during the entire period of reaction (Fig. 15), and the red shift of the 415-nm band and the increasing background absorbance with TOS observed in the other three experiments were not observed.

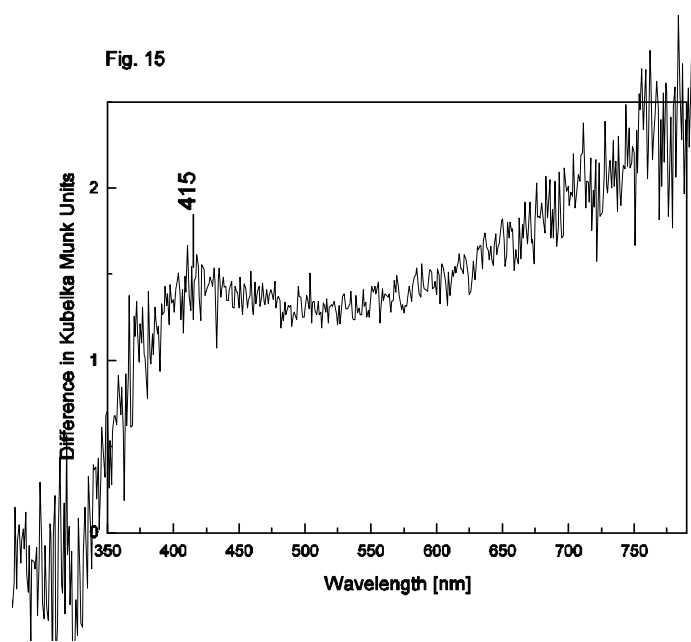

Fig. 15. UV-visible difference spectrum obtained after $75 \mathrm{~min}$ TOS in the isomerization reaction of n-pentane on $\mathrm{PtWZ}$ in the presence of $\mathrm{H} 2$.

\section{Discussion}

The observation of an induction period in the catalytic conversion of alkanes is not restricted to WZ catalysts; it has also been reported for reactions in liquid acids (28) and on the surface of SZ $(5,29,30)$. UV-visible spectra recorded during the isomerization of alkanes in the presence of these catalysts showed the growth of absorption bands during the induction period. Farcasiu and Lukinskas (28) detected bands at 270 and $300 \mathrm{~nm}$, assigned to cyclic or acyclic substituted polyalkenyl species (28). Similar species were observed on SZ by in-situ UV-visible spectroscopy; bands at 310 and $370 \mathrm{~nm}$, with a broad shoulder at $400 \mathrm{~nm}$, were reported and assigned to allyl cations and polyalkenyl species (30-32). The correlation between the growth of these bands and the development of the catalytic activity in the liquid acid led the authors (28) to propose that these species were involved in the catalytic reaction (although their exact role was not established).

\section{n-Pentane conversion catalyzed by $\mathrm{WZ}$ in the absence of $\mathrm{H}_{2}$}

Similar organic species may form on the WZ catalyst during the induction period of the reaction, but the band gap of the tungsten species lies at approximately $355 \mathrm{~nm}$, so that detection of bands at energies below $400 \mathrm{~nm}$ is hardly possible; only the band at $415 \mathrm{~nm}$ could be detected. We suggest that the red shift of this band observed with increasing TOS may originate from an increase of the chain length of the polyalkenyl species forming on the catalyst surface. In contrast to the experiments done with liquid acids (28) and SZ $(29,30)$, no direct correlation between the growth of the UVvis bands and the evolution of catalytic activity could be observed. A possible reason for the lack of such observa- 
tions may be the growth of the absorption with increasing TOS in the entire energy range beyond $350 \mathrm{~nm}$, which might have affected the band intensities. Possible reasons for the increasing absorption in the range beyond $350 \mathrm{~nm}$ are the formation of pregraphitic species (loosely referred to as "coke") (31) and the reduction (32-34) of the catalyst.

When the $n$-pentane conversion was carried out in the absence of $\mathrm{H}_{2}$ with the WZ catalyst, significant amounts of cracked products were observed, and the selectivity to isopentane was low (Fig. 1). At low conversions the formation of cracked products on solid acids such as zeolites can be explained (in simplified terms) by the formation of carbonium ion intermediates $(35,36)$ resulting from protonation of the alkane by Brønsted acid centers. The decomposition of the carbonium ion leads either to a carbenium ion and $\mathrm{H}_{2}$ or to a carbenium ion and an alkene and ultimately to cracked products. This monomolecular (Haag-Dessau) mechanism gives methane and ethane, among other products. Neither was observed in the presence of the WZ catalyst under our conditions, and we therefore rule out the formation of cracked products by the Haag-Dessau mechanism.

In previous investigations of the $n$-butane conversion catalyzed by SZ, the rates of formation of the various products showed different dependences on TOS (37). The difference between the TOS dependence of the rate of formation of the principal product, isobutane, and those of propane and pentanes was interpreted as evidence that a monomolecular mechanism competed with a bimolecular mechanism (involving a $\mathrm{C}_{8}$ intermediate).

In contrast to these observations, we found that in the case of $n$-pentane isomerization catalyzed by WZ for TOS > $15 \mathrm{~min}$, the ratios of the rates of formation of the various saturated (main) products remained essentially constant and independent of TOS. This result implies that a single reaction pathway rather than competing pathways could account for the products. The Haag-Dessau cracking mechanism is ruled out, and a simple monomolecular pathway proceeding via a $\mathrm{C}_{5}^{+}$cation (a carbenium ion) also seems unlikely, because the formation of the most important side products $\left(\mathrm{C}_{4}\right)$ can be explained only by an intermolecular mechanism, because the $\beta$-scission of a $C_{5}$ cation into methane and a $C_{4}$ cation is excluded because methane was not detected in the products.

The alternative bimolecular mechanism inferred to take place on $\mathrm{SZ}$ also seems improbable. The isomerization of $n$-pentane catalyzed by SZ gives high yields of $\mathrm{C}_{4}$ and $\mathrm{C}_{6}$ alkane side products, believed to be formed via a $\mathrm{C}_{10}$ intermediate $(13,38-40)$. In contrast to the conversion in the presence of SZ, in our work no hexane or other longer-chain alkanes were detected in the product, which argues against the bimolecular mechanism. To explain the fact that butanes and hexanes were not formed in equimolar amounts on SZ as predicted by the simple bimolecular mechanism, secondary cracking of hexanes was postulated (36). The higher reaction temperature employed with $\mathrm{WZ}$ could lead to smaller cracking products, which are thermodynamically favored over the longer-chain products, and the absence of hexane might be explained by quantitative cracking to give products with carbon numbers less than six. However, the small amount of propane formed does not support this suggestion.

In conclusion, on the basis of the observed product distributions, a $\mathrm{C}_{10}$ intermediate is regarded as highly unlikely, which implies that a bimolecular mechanism should be excluded.

A complex reaction pathway leading to cracked products during $n$-hexane isomerization reaction in the presence of trifluoromethanesulfonic acid was described by Farcasiu and Lukinskas (28), who reported the formation (after an induction period) of large amounts of cracked products, which could not be explained by a simple mono- or bimolecular mechanism. The appearance of these products was explained by a cracking side reaction (although methylpentanes can also be formed via this route), which, depending on the reaction conditions, can even become the dominant reaction. This so-called "cracking mode" showed a high selectivity for branched alkanes such as butane, pentane, and hexane. The authors (28) proposed the formation of organic "initiators" namely, substituted, mostly cyclic, polyalkenyl species formed from $n$-hexane by a one-electron oxidation by trifluoromethanesulfonic acid. These species somehow accelerate the catalytic reaction of the $n$-hexane to give cracked and rearranged products.

The "cracking mode" (28) shows some important similarities to the $n$-pentane isomerization on $\mathrm{WZ}$ as described in the present work, as follows:

1. An induction period is common to reaction in the liquid catalyst and ours.

2. Similar to the catalysis on WZ, for which isobutane is the most abundant side product, the "cracking mode" produced mainly branched alkanes.

3. The polyalkenyl species related to the "cracking mode" could not be detected directly on the WZ catalyst (see above). However, among the various types of organic deposits that could be observed during the reaction on WZ, some were characterized by absorption bands at wavelengths greater than $350 \mathrm{~nm}$ that may be attributed to longer-chain polyalkenyl species, and these might be involved in the reaction.

4. Farcasiu and Lukinskas (28) proposed the formation of polyalkenyl species via alkene intermediates formed by oxidative dehydrogenation leading to the reduction of the acid. In-situ EPR experiments characterizing the WZ catalyst (32) also indicated its reduction during the reaction of $n$-pentane, suggesting that the alkane might be activated via a redox step. The hydrogenation of propene observed in this work indicates that the reverse reaction, the dehydrogenation of an alkane, is also possible. The suggested formation of alkene intermediates is therefore regarded as realistic. Furthermore, pentenes were detected as 
products, and they might have been formed directly by dehydrogenation.

5. Farcasiu and Lukinskas (28) proposed that radicals might play a role since one-electron-transfer promoters such as iron and copper salts had an influence on the induction period in the liquid-phase reaction. The above-mentioned in-situ EPR experiments done with WZ (32) demonstrated that organic radicals are formed during the isomerization of $n$-pentane on WZ, and these possibly play a role in the reaction.

Because the observed product distributions cannot be explained readily by the classical monomolecular or bimolecular carbocation chemistry and because there are similarities between our observations and the "cracking mode," we propose that the reaction of $n$-pentane catalyzed by $\mathrm{WZ}$ in the absence of $\mathrm{H}_{2}$ is related to the organic deposits, presumably polyalkenyl species, on the catalyst surface. The polyalkenyl species might be formed on the catalyst surface as discussed above and possibly act as active sites for reaction by the "cracking mode" but their role in the chemistry is still not clear.

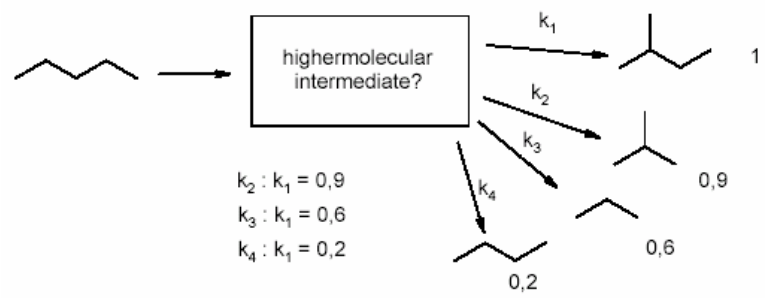

Scheme 1: Schematic representation of reaction path A.

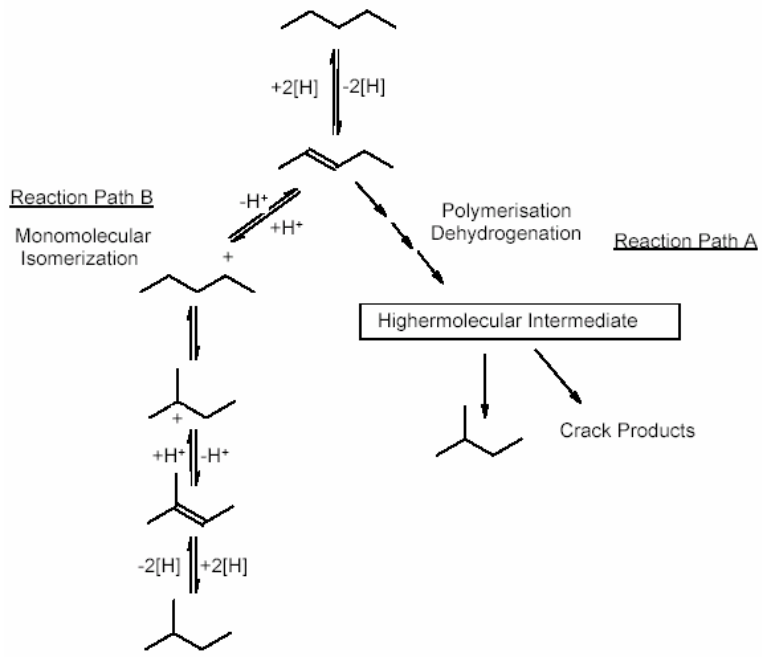

Scheme 2: Schematic representation of reaction path B (monomolecular isomerization) and of reaction path $\mathrm{A}$, which proceeds via higher-molecular-weight intermediates.

The presumed reaction path related to the organic deposits produces not only propane, isobutane and $n$-butane, but also isopentane. A possible explanation for the observed nearly constant selectivities for formation of the various products is that there is a common intermediate for all of them, as indicated in Scheme 1. A variation of the concentration of this intermediate with TOS would account for the observed changes in rate without changes in selectivity. The nature of this supposed intermediate remains unclear, but it must have a higher molecular weight than the intermediates in the rejected monomolecular and bimolecular mechanisms. This interpretation is supported by results of quenching experiments (10): when the reaction was interrupted within the induction period by purging with $\mathrm{He}$, the reaction could be restarted at an activity level close to that reached prior to quenching. This behavior can be explained by the suggestion that the deposits formed during the induction period remained after the feed flow was stopped (10). We refer to this reaction path involving a higher-molecular-weight intermediate as reaction path A (Scheme 2).

Rapid catalyst deactivation is often explained by the formation of high-molecular-weight aromatic structures referred to as coke (41). The postulated polyalkenyl species are expected to be precursors of the coke (42) that was detected on the WZ catalyst used for conversion of $n$-pentane (31). Coke deposits can increasingly block the catalyst surface with increasing TOS, leading to a decrease in the concentration of the intermediate in reaction path $\mathrm{A}$, consistent with the role of coke in deactivation of the catalyst.

\section{n-Pentane conversion catalyzed by $\mathrm{WZ}$ in the presence of $\mathrm{H}_{2}$}

When the reaction was catalyzed by WZ in the presence of $\mathrm{H}_{2}$, the most prominent products closely resembled those observed in the absence of $\mathrm{H}_{2}$ (Figs. 2 and 4). This observation leads to the inference that reaction path A plays an important role, with or without $\mathrm{H}_{2}$. The UV-visible spectra of the catalyst working in the presence of $\mathrm{H}_{2}$ (Fig. 14) also closely resemble those recorded in the absence of $\mathrm{H}_{2}$ and show the typical band at $415 \mathrm{~nm}$. This band, attributed to organic species participating in reaction path $\mathrm{A}$, was increasingly red-shifted with increasing TOS. The side products were mainly saturated, which implies that the unsaturated products had been hydrogenated. The data of Fig. 3 show that the presence of $\mathrm{H}_{2}$ leads to an increase in selectivity for the branched products with increasing TOS. Thus, the nearly constant ratios of the rates of formation of the side products to the rate of formation of the main product, isopentane, observed for reaction in the absence of $\mathrm{H}_{2}$, were not observed when $\mathrm{H}_{2}$ was present.

The presence of $\mathrm{H}_{2}$ in the reactants at temperatures > $473 \mathrm{~K}$ was shown to cause partial reduction of the tungstates with formation of $\mathrm{W}^{5+}$ centers and $\mathrm{OH}$ groups (32). We propose that the reduction of the tungstates in PtWZ by $\mathrm{H}_{2}$ opens up a new reaction path for a highly selective monomolecular isomerization, denoted reaction path $\mathrm{B}$ (Scheme 2); evidence for this proposal is developed below. We infer that selective reaction path $\mathrm{B}$ taking place on catalyst $\mathrm{WZ}$ in the presence of $\mathrm{H}_{2}$ in parallel with the unselective reaction path A enhances the selectivity for isopentane formation. 


\section{n-Pentane conversion catalyzed by prereduced $\mathrm{WZ}$}

Pre-reduction of the catalyst prior to its use for isomerization of $n$-pentane leads to enhanced activity and isopentane selectivity at low TOS (Fig. 5). As a result of the prereduction at $673 \mathrm{~K}$, large amounts of hydrogen are stored in the bronze-like surface tungstates (32). We infer that this hydrogen leads to a short lifetime and low concentrations of unsaturated intermediates on the catalyst, making possible the fast and selective monomolecular reaction path $\mathrm{B}$ and explaining the relatively high activity and selectivity at low TOS. As a consequence of the continuous loss of hydrogen from the catalyst, the unsaturated intermediates increasingly polymerize, and the typical cracking products of reaction path A become important. Therefore, according to this interpretation, the rate of isopentane formation does not show any induction period but decreases continuously with increasing TOS, corresponding to the observations.

\section{$n$-Pentane conversion catalyzed by PtWZ in the absence of $\mathbf{H}_{2}$}

When the catalysis by PtWZ was carried out with no $\mathrm{H}_{2}$ in the feed, the activity and selectivity were found to be roughly the same as the values observed in experiments with WZ in the absence of $\mathrm{H}_{2}$ (Figs. 7 and 8). The rates of formation decreased in the order isobutane $>$ propane $>$ butane, implying that reaction path A was predominant. This inference is confirmed by the UV-visible spectra of the PtWZ catalyst, which resemble those of WZ. The band at $415 \mathrm{~nm}$ attributed to species associated with reaction path A was observed, and with increasing TOS it showed the typical red shift that is inferred to be related to catalyst deactivation.

The overall rate of the conversion catalyzed by PtWZ was found to be higher than that catalyzed by WZ, which is inferred to be a consequence of the high pentene formation rate on PtWZ. Before contacting of the PtWZ catalyst with the reactants, platinum was present in the oxidation states II and IV $(32,33,43,44)$, possibly present in small $\mathrm{PtO}_{\mathrm{x}}$ clusters or even atomically dispersed. The observed effects might be explained by the suggestion that platinum was partially reduced (possibly by autoreduction) under reaction conditions, leading to the observed dehydrogenation activity. We introduce the term reaction path $\mathrm{C}$ to refer to catalysis in the presence of partially reduced platinum.

\section{$n$-Pentane conversion catalyzed by PtWZ in the presence of $\mathbf{H}_{2}$}

The data reported here confirm the exceptionally high activity and selectivity of PtWZ in the presence of $\mathrm{H}_{2}$ (7,8,20-26). Our data show that the conversion of $n$-pentane in the presence of PtWZ is 60 times higher than the maximum conversion observed for WZ under identical conditions, and the isopentane selectivity is greater than $95 \%$ (Fig. 9) under our conditions.

The UV-visible spectra recorded during the reaction on PtWZ in the presence of $\mathrm{H}_{2}$ are characterized by a greater overall absorption than was observed in the other experiments (Fig. 15). The greater overall absorption can be explained by the formation of metallic platinum, accelerated by hydrogen in the feed (34). The appearance of the band at $415 \mathrm{~nm}$ indicates the formation of polyalkenyl species or coke. One might infer from the spectra (Fig. 15) that, in the presence of platinum and $\mathrm{H}_{2}$ together, the polyalkenyl species are removed by reaction nearly as fast as they are formed, being present in such low concentrations that they have a negligible effect on the catalysis.

In previous work (34) we showed that the promotion by platinum leads to a deeper reduction of the surface tungstates by $\mathrm{H}_{2}$, leading to $\mathrm{W}^{5+}$ and $\mathrm{OH}$ groups. This reduction facilitates the desorption of unsaturated intermediates from the tungstates via hydrogenation. According to this inference, the unselective reaction path A, which is associated with the presence of polyalkenyl species, is then suppressed because the $\mathrm{C}_{5}$ intermediates largely desorb before they can undergo condensation/polymerization reactions. Instead, the monomolecular isomerization (reaction path B) takes over, which leads to the observed high activity and selectivity for isopentane (Scheme 2). The fast isomerization reaction, however, remains possible prior to the desorption of the $\mathrm{C}_{5}$ intermediates, accounting for the observed high yields of branched isomers.

These mechanistic features are in general accord with the interpretations given in the literature. However, there are two different reported explanations for the promoting effect of platinum:

1. Some authors $(20,21)$ attribute the promotion effect of the platinum to its dehydrogenation activity. The alkanes are presumably activated by dehydrogenation, and the resultant alkenes are isomerized on Brønsted acidic centers. Because alkenes are much more basic than alkanes, they can be protonated by moderately strong Brønsted acid centers of the tungsten phase. This mechanism represents classical bifunctional catalysis involving a metal and acidic sites. Concomitant with the reaction of the alkane, the hydrogen is believed to adsorb dissociatively on the platinum and lead to the hydrogenation of alkenes to form alkanes. Furthermore, the surface hydrogen can hydrogenate the coke.

2. A different version of the bifunctional mechanism was reported by Iglesia et al. $(7,22)$ and Barton et al. $(8,23)$, who suggested that the role of the platinum is essentially only the activation of the $\mathrm{H}_{2}$. The $\mathrm{H}_{2}$ is inferred to adsorb dissociatively on the platinum and to reduce the tungsten phase by hydrogen spillover. This reduction of the tungsten phase by the activated $\mathrm{H}_{2}$ is inferred to lead to the formation of $\mathrm{W}^{5+}$ centers and $\mathrm{OH}$ groups $(31,33)$. The "stored" hydrogen converts the carbenium ions to alkanes, which desorb. Two electrons and one proton are transferred in this desorption step, and the adsorbed carbenium ion is replaced by a proton. The high selectivity of this mechanism is explained by the fast "hydrogen transfer rates 
which lead to short surface lifetimes, to low steady-state coverage of the surface by carbocations and to desorption of carbocations before $\beta$ scission" (7). The strong enhancement of the activity caused by the presence of $\mathrm{H}_{2}$ and $\mathrm{Pt}$ is explained by the facilitation of the desorption step, which becomes quasi equilibrated and is, therefore, no longer rate determining $(7,8,22,23)$.

The significant difference between the two interpretations is that according to the first the alkanes are activated on and desorbed from the platinum particles, whereas according to the second these processes occur on the tungsten species. An experimental test to distinguish between the two reaction routes proposed for PtWZ is difficult because analogous intermediates (adsorbed carbenium ions, adsorbed alkenes) are involved in both cases. Therefore, the same product distribution may be expected for both proposed reaction routes, which makes it impossible to discriminate between them on this basis. It is even possible that both take place simultaneously. The fact that the unpromoted WZ without a metallic function shows catalytic activity (although it is very low) suggests the validity of the proposal of activation/desorption of the alkanes on the tungsten species $(7,8,22,23)$. The reduction of the tungsten species by $\mathrm{H}_{2}$ homolytically dissociated on platinum plays a decisive role in the interpretation $(7,8,22,23)$, and in earlier work we directly demonstrated the formation of $\mathrm{W}^{5+}$ centers and $\mathrm{OH}$ groups on the catalyst in the presence of $\mathrm{H}_{2}(32,34)$. The aforementioned authors $(7,8,22,23)$ gave no explanation for how the carbenium ions are formed, and we infer that even the unpromoted catalyst without a metallic function is capable of activating the alkanes, possibly via formation of alkenes. Although dehydrogenation on the metallic function cannot be excluded entirely, the arguments presented here rather suggest an activation/desorption (dehydrogenation/hydrogenation) on the tungsten species through the oxidation/reduction of the $\mathrm{W}^{5+} / \mathrm{W}^{6+}$ system, as indicated in Scheme 3.

$$
\begin{aligned}
& \mathrm{n}\left(\mathrm{WO}_{\mathrm{x}}\right)+\mathrm{yH}_{2} \rightleftharpoons(\mathrm{HO})_{2 y}\left(\mathrm{~W}^{5+}{ }_{2 y}\right)\left(\mathrm{WG}^{6+}{ }_{n-2 y}\right) \mathrm{O}_{x n-2 \mathrm{y}}
\end{aligned}
$$

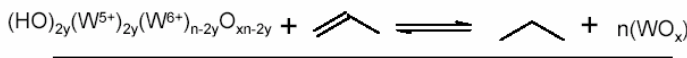

$$
\begin{aligned}
& \mathrm{H}_{2}+\Upsilon \rightleftharpoons
\end{aligned}
$$

Scheme 3: Schematic representation of the catalytic hydrogenation of propene via surface tungsten species.

The product distribution observed during the isomerization catalyzed by PtWZ in the presence of $\mathrm{H}_{2}$ is completely different from those observed with $\mathrm{WZ}$ with and without $\mathrm{H}_{2}$ and with PtWZ in the absence of $\mathrm{H}_{2}$. The side products contained mainly ethane/propane and methane/butanes in equimolar amounts, respectively. These products are typical for hydrogenolysis of pentane as observed with numerous oxide-supported platinum catalysts $\mathrm{Pt} / \mathrm{MO}_{\mathrm{x}}(\mathrm{M}=\mathrm{Al}$ (43-46), Si (47,48), Mg (49), Ti (50), Ce/Ti (51)). We therefore propose that the ethane/propane and the methane/butane side products are formed directly on platinum particles without the involvement of the tungsten species. This interpretation was proposed by Yori et al. (20), and these same authors reported that $\mathrm{Pt} / \mathrm{ZrO}_{2}$, in contrast to PtWZ, shows a high selectivity for the hydrogenolysis products. The proposal is also in accord with the observation that the rates of formation of the hydrogenolysis products show a dependence on TOS different from that of the main product, isopentane. Furthermore, it explains why more $n$-butane than isobutane is formed whereas for a typical acid-catalyzed cracking reaction the opposite is observed. Whereas isobutane is preferentially formed via reaction pathway $\mathrm{A}$, the hydrogenolysis on platinum produces $n$-butane preferentially. This hydrogenolysis reaction is independent of the isomerization reaction (reaction path $\mathrm{B}$ ) and is denoted reaction path $\mathrm{D}$. On $\mathrm{Pt} / \mathrm{MO}_{\mathrm{x}}$ catalysts, isomerization is generally observed to take place in parallel with hydrogenolysis. Therefore, reaction path $\mathrm{D}$ possibly produces isopentane as well as the hydrogenolysis products. However, as reaction path $\mathrm{D}$ occurs only in parallel with the isomerization reaction (reaction path B), it is not clear whether isopentane is produced at a significant rate by this route.

\section{n-Pentane conversion catalyzed by prereduced PtWZ}

Prereduction of the PtWZ catalyst led to the conversion of $\mathrm{Pt}^{2+/ 4+}$ to metallic platinum particles, (34) (Figs. 11 and 12). If the only role of $\mathrm{H}_{2}$ were to cause the reduction of Pt cations to metallic platinum, then one might expect a similar activity and selectivity for the pentane conversion in the presence and in the absence of $\mathrm{H}_{2}$ when the catalyst had been prereduced. However, a sharp decrease of the activity and a continuous reduction of the selectivity were observed as a function of TOS in the absence of $\mathrm{H}_{2}$. During prereduction at $673 \mathrm{~K}, \mathrm{H}_{2}$ is stored in the tungsten species (bronzelike structures) with creation of $\mathrm{W}^{5+}$ and $\mathrm{OH}$ groups. The increasing consumption of the stored $\mathrm{H}_{2}$ through desorption is inferred to lead to the accumulation of the reactive intermediates (alkenes), which causes a shift from reaction paths $\mathrm{A}$ and $\mathrm{B}$ to reaction paths $\mathrm{C}$ and $\mathrm{D}$. We infer that the conversion at the moment of the first product analysis after $7 \mathrm{~min}$ TOS was only about one third of that observed when the reaction was carried out in the presence of $\mathrm{H}_{2}$, because most of the stored $\mathrm{H}_{2}$ had already been consumed.

The main side products observed during $n$-pentane conversion catalyzed by prereduced PtWZ were pentenes formed presumably by direct dehydrogenation on the metallic platinum particles. Because of the competition involving the four reaction paths, the product distribution is complex and difficult to account for quantitatively. But with increasing TOS, the product distribution approached that corresponding to reaction path A (isobutane > propane > $n$-butane) and $\mathrm{C}$ (pentenes $>$ several unsaturated and saturated cracking products).

Table 2 shows a summary of the postulated reaction paths observed in catalysis by WZ and PtWZ. Whereas only reaction paths $\mathrm{A}$ and $\mathrm{B}$ are possible on the $\mathrm{WZ}$ catalyst, reaction paths $\mathrm{C}$ and $\mathrm{D}$ were observed when the catalyst was PtWZ. We suggest that the observed product distributions 
can be explained by combinations of these paths. The importance of each is dependent on the reaction conditions (temperature, partial pressure of $\mathrm{H}_{2}$, etc.). Specifically, when the reaction is catalyzed by $\mathrm{WZ}$ in the absence of $\mathrm{H}_{2}$, only reaction path A pertains, and reaction path $\mathrm{B}$ becomes possible when $\mathrm{H}_{2}$ is added to the feed. When the catalyst is PtWZ and

Table 2: Reaction paths postulated for $\mathrm{WZ}$ and PtWZ catalysts.

\begin{tabular}{|c|c|c|}
\hline $\begin{array}{c}\text { reaction } \\
\text { path }\end{array}$ & type of reaction & products \\
\hline$A$ & $\begin{array}{c}\text { Complex reaction related to } \\
\text { organic deposits }\end{array}$ & $\begin{array}{l}\text { Isopentane, isobutane, propane and } \\
n \text {-butane in ratio } 1: 0.9: 0.6: 0.2 \\
\text { unsaturated cracking products }\end{array}$ \\
\hline $\mathrm{B}$ & Monomolecular isomerization & Isopentane \\
\hline $\mathrm{C}$ & $\begin{array}{l}\text { Dehydrogenation, } \\
\text { isomerization, and cracking on } \\
\text { the platinum particles }\end{array}$ & $\begin{array}{c}\text { Pentenes, saturated and unsaturated } \\
\text { cracking products, isopentane }\end{array}$ \\
\hline $\mathrm{D}$ & $\begin{array}{l}\text { Hydrogenolysis and possibly } \\
\text { isomerization on platinum } \\
\text { particles }\end{array}$ & $\begin{array}{l}\text { Methane and butane, and ethane and } \\
\text { propane }{ }^{a}\end{array}$ \\
\hline
\end{tabular}

the reaction occurs in the absence of $\mathrm{H}_{2}$, reaction paths $\mathrm{A}$ and $\mathrm{C}$ dominate, and when $\mathrm{H}_{2}$ is added, reaction paths $\mathrm{B}$ and D take over.

\section{Conclusions}

The $n$-pentane conversion catalyzed by unpromoted WZ in the absence of $\mathrm{H}_{2}$ is characterized by only low activity and selectivity, accounted for by a complex reaction path (A) producing mainly cracked products, isobutane, propane, and $n$-butane. This reaction path is associated with organic surface species on the catalyst, probably polyalkenyls. The alkanes are inferred to be activated on the surface tungstates through a redox step and oligomerize/condense to form the polyalkenyls. The UV-visible spectra show a band at $415 \mathrm{~nm}$ which is red-shifted with increasing TOS and which is attributed to increasing chain length of the surface hydrocarbon species.

Addition of $\mathrm{H}_{2}$ to the feed has only a minor effect on the unselective reaction path $\mathrm{A}$, with the selectivity to isopentane being slightly increased. This selectivity enhancement is attributed to the slight reduction of the surface tungstates (with formation of $\mathrm{W}^{5+}$ centers and $\mathrm{OH}$ groups), which permit a contribution of the selective monomolecular isomerization path $\mathrm{B}$ to the product distribution.

The promoted catalyst PtWZ in the absence of $\mathrm{H}_{2}$ is slightly more active than WZ. The product distribution shows the typical cracked products of reaction path $\mathrm{A}$. The UV-visible spectra include the 415-nm band, which is redshifted with increasing TOS and which characterizes the organic deposits associated with reaction path A. The enhanced overall activity is mainly caused by an additional reaction path (C) taking place on the partly reduced $\mathrm{PtO}_{\mathrm{x}}$ particles, which produces pentenes and saturated as well as unsaturated cracked products.

Addition of $\mathrm{H}_{2}$ to the feed to a reactor containing PtWZ leads to a marked increase in the activity and selectivity; the conversion was 60 times that observed with the WZ catalyst under identical conditions, and the isopentane selectivity was $>95 \%$. The unselective reaction path A was completely suppressed, and the fast and highly selective monomolecular reaction path $\mathrm{B}$ became dominant. In reaction by this path, the alkanes are activated on the surface tungstates to form unsaturated intermediates. The reduction of the surface tungstates to $\mathrm{W}^{5+}$ and $\mathrm{OH}$ groups permits the unsaturated intermediates adsorbed on the surface tungstates to desorb rapidly via hydrogenation. The formation of polalkenyl species on the surface is thus minimized, leading to the suppression of reaction path A. The fast isomerization reaction, however, remains possible prior to the desorption of the $\mathrm{C}_{5}$ intermediates and leads to the selective formation of isopentane. 
The side products observed are typical of hydrogenolysis reactions. We infer that small amounts of these side products are formed by an independent hydrogenolysis pathway taking place on the platinum particles.

\section{Acknowledgments}

The work done in Munich was supported by the Deutsche Forschungsgemeinschaft (SFB 338). PL is grateful for a fellowship from the Alexander von Humboldt-Stiftung and also thanks Prof. Dr. R. Schlögl, Fritz Haber-Institut der Max Planck-Gesellschaft, for financial support. The cooperation involving the University of California at Davis and the University of Munich was made possible by a Humboldt Senior Scientist Award to BCG and a Max Planck Award to HK, granted by the Max Planck-Gesellschaft and the Alexander von Humboldt-Stiftung.

\section{References}

(1) Hino, M., and Arata, K., J. Chem. Soc., Chem. Commun. 851 (1980).

(2) Hsu, C.-Y., Heimbuch, C. R., Armes, C. T., and Gates, B. C., J. Chem. Soc, Chem. Commun. 1645, (1992).

(3) Chen, F. R., Coudurier, G., Joly, J. F., and Vedrine, J. C., J. Catal. 143, 616 (1993).

(4) Adeeva, V., Lei, G. D., and Sachtler, W. M. H., Catal. Lett. 33, 135 (1995).

(5) Spielbauer, D., Mekhemer, G. A. H., Bosch, E., and Knözinger, H., Catal. Lett. 36, 59 (1996).

(6) Hino, M., and Arata, K., J. Chem. Soc., Chem. Commun. 1259 (1987).

(7) Iglesia, E., Barton, D. G., Soled, S. L., Miseo, S., Baumgartner, J. E., Gates, W. E., Fuentes G. A., and Meitzner, G. D., Stud. Surf. Sci. Catal. 101, 533 (1996)

(8) Barton, D. G., Soled, S. L., Meitzner, G. D., Fuentes, G. A., and Iglesia, E., J. Catal. 181, 57 (1999).

(9) Scheithauer, M., Grasselli, R. K., and Knözinger, H., Langmuir 14, 3019 (1998).

(10) Scheithauer, M., Cheung, T.-K., Jentoft, R. E., Grasselli, R. K., Gates, B. C., and Knözinger, H., J. Catal. 180, 1 (1998).

(11) Li, B., and Gonzales, R. D., Appl. Catal. A 174, 109 (1998).

(12) Ng, T. T., and Horvat, H., Appl. Catal. 123, 197 (1995).

(13) Xu, B. Q., and Sachtler, W. M. H., J. Catal. 167, 224 (1997).

(14) Kuba, S., Gates, B. C., Vijayanand, P., Grasselli, R. K. and Knözinger, H., Chem. Commun. 507 (2001).

(15) Lukinskas, P., Kuba, S., Grasselli, R. K., and Knözinger, H., to be published.

(16) Boyse, R. A., and Ko, E. I., J. Catal. 171, 191 (1997).

(17) Gazzoli, D., Valigi, M., Dragone, R., Marucci, A., and Mattei, G., J. Phys. Chem. B 101, 11129 (1997).

(18) Santiesteban, J. G., Vartuli, J. C., Han, S., Bastian, R. D., and Chang, C. D., J. Catal., 168, 431 (1997).

(19) de Rossi, S., Giovanni, F., Valigi, M., and Gazzoli, D., Appl. Catal. A 231, 159 (2002).

(20) Yori, J. C., Pieck, C. L., and Parera, J. M., Appl. Catal. A 181, 5 (1999).

(21) Yori, J. C., Pieck, C. L., and Parera, J. M., Stud. Surf. Sci. Catal. 130, 2441 (2000).

(22) Iglesia, E., Barton, D. G., Biscardi, J. A., Gines, M. J. L., and Soled, S. L., Catal. Today 38, 339, (1997)

(23) Barton, D. G., Soled, S. L., and Iglesia, E., Top. Catal. 6, 87 (1998).

(24) Santiesteban, J. G., Calabro, D. C., Borghard, W. S., Chang, C. D., Vartuli, J. C., Tsao, Y. P., Natal-Santiago, M. A., and Bastian, R. D., J. Catal. 183, 314 (1999).

(25) Comelli, R. A., Canavese, S. A., and Fígoli, N. S., Catal. Lett. 55, 177 (1998).

(26) Falco, M. G., Canavese, S. A., Comelli, R. A., and Fígoli, N. S., Appl. Catal. A 201, 37 (2000).

(27) Thiede,M., and Melsheimer, J., Rev. Sci. Instrum. 73, 394 (2002).

(28) Farcasiu, D., and Lukinskas, P., J. Chem. Soc., Perkin Trans. 2, 2715 (1999).

(29) Chen, F. R., Coudurier, G., Joly, J. F., and Vedrine, J. C., J. Catal. 143, 616 (1993).

(30) Ahmad, R., Melsheimer, J., Jentoft, F., and Schlögl, R., in preparation.

(31) Kuba, S., and Knözinger, H., J. Raman Spectr. 33, 325 (2002).

(32) Kuba, S., Concepción, P. H., Grasselli, R. K., Gates, B. C., Che, M., and Knözinger, H., Phys. Chem. Chem. Phys. 3, 146 (2001).

(33) Arribas, M. A., Márquez, F., and Martínez, A., J. Catal. 190, 309 (2000).

(34) Kuba, S., Che, M., Grasselli, R. K., and Knözinger, H., J. Phys. Chem. B 107, 3459 (2003).

(35) Haag, W. O. and Dessau, R. M., Proc. 8th Int. Congr. Catal., Berlin, Vol. 2, Dechema, Frankfurt am Main, 1984, p. 305.

(36) Kotrel, S., Knözinger, H., and Gates, B. C., Microporous Mesoporous Mater. 35-36, 11 (2000).

(37) Matsuhashi, H., Shibata, H., Nakamura, H., and Arata, K., Appl. Catal. A 187, 99 (1999).

(38) Rezgui, S., Jentoft, R. E., and Gates, B. C., Catal. Lett. 51, 229 (1998).

(39) Rezgui, S., and Gates, B. C., Catal. Lett. 37, 5 (1996).

(40) Adeeva, V., Liu, H. Y., Xu, B. Q., and Sachtler, W. M. H., Top. Catal. 6, 165 (1998).

(41) Li, B., and Gonzales, R. D., Appl. Catal. A 174, 109 (1998).

(42) Sommer, J., Sassi, A., Hachoumy, M., Jost, R., Karlson, A., and Ahlberg, P., J. Catal. 171, 391 (1997).

(43) Boutonnet, M., Kizling, J., Touroude, R., Maire, G., and Stenius, P., Catal. Lett. 9, 347 (1991).

(44) Corolleur, C., Corolleur, S., and Gault, F. G., J. Catal. 24, 385 (1972).

(45) Leclercq, G., Leclercq, L., and Maurel, R., J. Catal. 50, 87 (1977).

(46) Garin, F., and Gault, F. G., J. Am. Chem. Soc. 97, 4466 (1975).

(47) Guczi, L., Matusek, K., and Eszterle, M., J. Catal. 60, 121 (1979).

(48) Guczi, L., Matusek, K., Margitfalvi, J., Eszterle, M., and Till, F., Acta Chim. Acad. Sci. Hung. 101, 107 (1979)

(49) Clarke, J. K., Bradley, M. J., Garvie, L. A., Craven, A., and Baird, J. T., J. Catal. 143, 122 (1993).

(50) Anderson, J. B., Burch, R., and Cairns, J. A., J. Chem. Soc., Chem. Commun. 1647 (1986).

(51) Dauscher, A., and Maire, G., J. Mol. Catal. 69, 259 (1991). 